\title{
MORE EVIDENCE ON THE ATTRACTION OF MALES TO THE FEMALE SEX PHERMONE OF Opisina arenosella" walker:
}

\section{L.C.P. Fernando and K.A.S. Chandrasiri \\ Coconut Research Institute, Lunuwila, Sri Lanka}

Coconut caterpillar, (Opisina arenosella) is a serious pest causing up to about $80 \%$ yield loss in coconut in Sri Lanka (Perera, 1987). Since, it's first appearance in Batticaloa district (Eastern province), around the turn of the century, has now spread to Western, Southern, North-Westem and Central provinces. An average of 250-500 ha of coconut are being annually infested while half of that extent is subjected to treatment with insecticides. The primary reason for outbreaks is climatic conditions. The low minimum temperatures that prevail during the October to February period is detrimental to both the pest and it's natural enemies, particularly parasitoids. At the end of the adverse period, the pest increases rapidly while the parasitoids fail to do so for another 3-4 months. This time lag causes the pest outbreak and at these pest levels, parasitoid numbers are insufficient to exert control. Therefore, if parasitoids could be augmented at the initial stages of an infestation there are high chances of preventing onset of outbreaks. To augment laboratory-bred parasitoids it is essential to predict when and where early infestations occur since, the pattern and distribution of the infestations vary considerably each year.

The presence of a female sex pheromone in coconut caterpillar, Opisina arenosella (Lepidoptera : Oecophoridae) has been revealed from studies in India (Murthy et al., 1995) and in Sri Lanka (Mumford et al., 1986). Although, some evidence was present in the preliminary studies carried out in Sri Lanka, the results were not conclusive since, there was no significant difference in the number of male moths caught in virgin female-baited traps and unbaited traps.: Hawever, baited traps caught more males than females. Therefore, further studies were undertaken to ascertain the attraction of virgin females of Opisina arenosella to conspecific males. Here we present our investigations. 
A

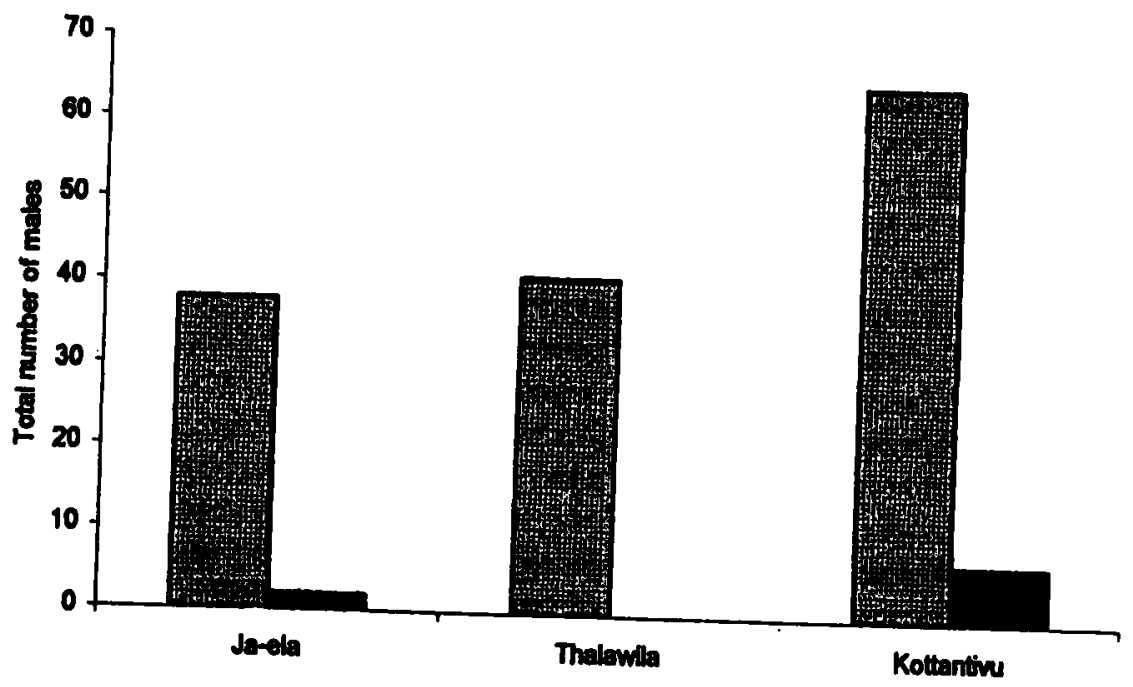

B

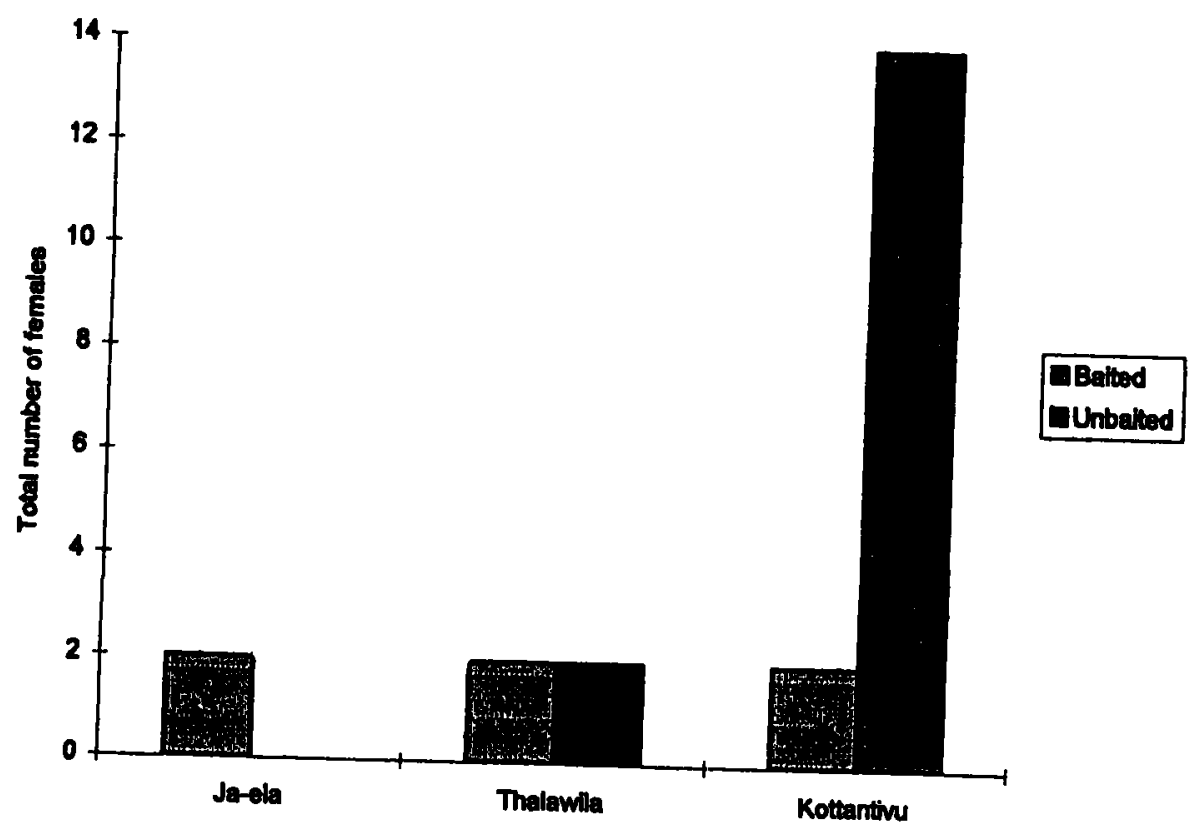
Figure 1: Total number males (A) and females (B) of Opsina areuosella caught in baited and unbaited traps
a Ja-ela, Thalawila and Kottantivu for two consecutive days 
The experiment was carried out in three estates in Ja-ela, Thalawila and Kottantivu infested by coconut caterpillar during the périod November to December, 1996. One to two day old virgin females were individually confined in net cages of lî diameter and 4î tall. Each cage was fixed between two square (8î x 8î) thlick plastic sheets held 4î apart. Inner surfaces of the sheets were applied with insect glue to trap the moths attracted to the virgin females. The size of the traps in the present experiment was reduced to one fourth of that used in the experiments of Mumford et al. (1986) to minimize accidental catches. The traps (Isandwich trapsi) were placed horizontally in the canopy of the infested trees for two consecutive nights. Each of 10 baited and unbaited traps were set at each location. The trap catches of males and females were recorded at the end of the two days.

The number of male moths caught in baited traps was significantly higher $(\mathrm{P}<0.001)$ than in unbaited traps (Fig. 1.A): The number of female moths caught in both trap types was nearly equal, with the exception in traps at Kottantivu indicating these were accidental caiches (Fig. 1B). Hence, the results conclusively revealed the attractiveness of virgin femaies to conspecific males of Opisina arenosella clearing the doubts of the earlier experiments.

Synthetic analogues of sex pheromones have been used to forecast and monitor pest populations. Similarly the synthetic sex pheromone of Opisina arenosella would help to forecast time and location of coconut caterpillar pest infestations in time sufficient enough to employ parasitoids and thereby prevent development of outbreaks. The components of the pheromone has been identified by Hall (1986, unpublished report): Therefore further studies are necessary to identify the natural blend of the pheromone and its effectiveness in the field conditions.

\section{REFERENCES}

Mumford, J. D., Hall, D. R., Perera, P. A. C. R. and Kanagaratnam, P. (1986) Annual report of the Crop Protection Division, Coconut Research Insti tute of Sri Lanka.

Murthy, K.S., Gour, T.B., Reddy, D.D.R., Babu, T.R: and Zaheruddeen, S.M. (1995). Pheromone baits for coconut black headed caterpillar, Opisina arenosella walker. Insect Environment. 1:3-4.

Perera, P. A. C. R: (1987). Sudies on Opisina arenosella Walker and it's natu ral enemies in Sri Lanka. Ph D thesis. University of London. 